\title{
Government and Opposition
}

http://journals.cambridge.org/GOV

Additional services for Government and

\section{Opposition:}

Email alerts: $\underline{\text { Click here }}$ Subscriptions: Click here Commercial reprints: Click here

Terms of use : $\underline{\text { Click here }}$

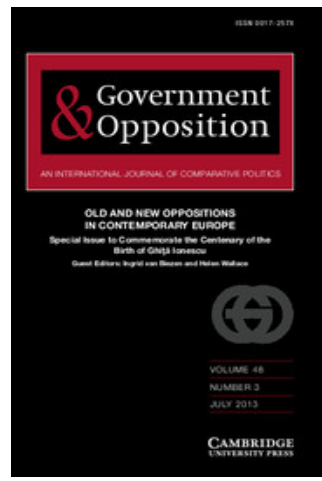

\section{The Changing Basis of Party Competition: Education, Authoritarian-Libertarian Values and Voting}

\section{Rune Stubager}

Government and Opposition / Volume 48 / Special Issue 03 / July 2013, pp 372 397

DOI: 10.1017/gov.2013.13, Published online: 05 June 2013

Link to this article: http://journals.cambridge.org/ abstract S0017257X13000134

How to cite this article:

Rune Stubager (2013). The Changing Basis of Party Competition:

Education, Authoritarian-Libertarian Values and Voting. Government and Opposition, 48, pp 372-397 doi:10.1017/gov.2013.13

Request Permissions : $\underline{\text { Click here }}$ 


\title{
The Changing Basis of Party Competition: Education, Authoritarian-Libertarian Values and Voting
}

\begin{abstract}
The role of social structure as a determinant of electoral behaviour has been debated across Western countries, with one side in the debate arguing that the rise of the electoral conflict between authoritarian-libertarian values reflects the diminishing importance of socio-structural factors. In contrast, this article shows, using a unique representative sample from Denmark, how this conflict has its roots in an opposition between high- and low-education groups that divide over authoritarian-libertarian values, have developed education-based identities and group consciousness, and are influenced by these factors to vote for parties, each mobilizing their side in the conflict - that is, that the authoritarian-libertarian conflict is based on an education cleavage. Documenting for the first time the influence of education-based identity and group consciousness on voting, these findings demonstrate that socio-structural factors - partly through the voters' social identities and consciousness - continue to play an important role for electoral behaviour in Western countries. Likewise, the findings suggest that the conflict over authoritarian-libertarian values will have lasting importance for politics in these countries. The logical next step, therefore, will be to extend the analyses to the comparative level.
\end{abstract}

ACROSS WEST EUROPEAN COUNTRIES THE PAST FEW DECADES HAVE seen an increase in the electoral importance of a range of new issues, such as abortion, immigration and criminal justice - all of which are related to the same underlying dimension often labelled authoritarian-libertarian values (Flanagan 1987; Flanagan and Lee 2003; Kitschelt 1994, 1995; Kriesi et al. 2008; Stubager 2010). This development has been paralleled by an ongoing scholarly debate about the relevance of individuals' social backgrounds and social identities to their political behaviour. One side in the debate has

* Rune Stubager is Associate Professor in the Department of Political Science at Aarhus University. Contact email: stubager@ps.au.dk.

(C) The Author 2013. Published by Government and Opposition Limited and Cambridge University Press 
argued that the new values have replaced social class and other traditional cleavages as fundamental drivers of electoral behaviour (see, for example, Dalton 2002; Inglehart 1997), while others have argued for a continuing relevance of factors such as class (Evans 1999), related to the economic conflict that dominated politics in Western countries for most of the twentieth century (Ionescu 1975).

While many, although certainly not all, analysts agree that class voting is on the decline (Clark and Lipset 1991), this does not imply that social background and identity have become irrelevant to electoral politics. Not only may class voting continue to exist on a (possibly) smaller scale than previously (see Best 2011), but other features of individuals' backgrounds such as race may also continue to play important roles (McDermott 2009) just as hitherto neglected social groupings may assume increasing influence. It is the latter possibility that is explored in this article.

Research in a multitude of countries has repeatedly shown that education is the strongest single predictor of individuals' positions on authoritarian-libertarian values, with higher levels of education leading to more libertarian positions and vice versa (Bovens and Wille 2010; Houtman et al. 2008; Stephens and Long 1970; Stubager 2008; van der Waal et al. 2007; Weakliem 2002; van de Werfhorst and de Graaf 2004). In addition, recent research (Stubager 2009a) has shown that the objective value conflict between educational groups is reflected at the subjective level in the form of a development of identity and consciousness around those groups. Given the rising electoral importance of authoritarian-libertarian values, this suggests that education and the social identity and consciousness associated with it may constitute an important new social anchor for electoral behaviour - an anchor that has not been properly explored so far.

Based on cleavage theory and using a unique data set, this article addresses this shortcoming and demonstrates that education and education-based social identity and consciousness do play such anchoring roles not only at the level of (authoritarian-libertarian) values, but also in relation to individuals' electoral behaviour with regard to parties that mobilize the opposing groups. In other words, the conflict over authoritarian-libertarian values has its roots in a fully fledged education cleavage.

Thereby, this analysis adds to existing knowledge in two ways. First, the investigation of the importance of education and, for the 
first time, education-based identity and consciousness for people's electoral choices constitutes new evidence that social structure is still important for electoral behaviour in advanced Western societies. Second, the identification of a structural anchor to the authoritarian-libertarian conflict provides a deeper understanding of the conflict, its content and likely duration. The results presented below indicate that the conflict is of a fairly stable nature. It looks set, in other words, to influence politics in Western countries for years to come (see also Casal Bértoa 2013).

The analyses are conducted on a specially collected representative survey of the Danish electorate, which makes an interesting case in the present context. On the one hand, Henjak (2010) argues that Danish history constitutes an unfavourable setting for the development of an education cleavage. This is due to the encompassing social democratic welfare state, which alleviates the conflict between winners and losers of globalization that gives rise to a cultural cleavage in other countries, and to the weak pre-existing cultural cleavages (such as centre-periphery) from which a new cultural cleavages could develop. On the other hand, the level of social development in combination with the open political system with a threshold of only 2 per cent for entering parliament means that Danish society is open to new social and political influences (Stubager 2010). Given this background, Denmark constitutes a critical case for the establishment of such a cleavage in the sense that, if the cleavage has not materialized here, it becomes difficult to see it developing in other contexts.

In what follows, I first briefly discuss the content of the authoritarian-libertarian value dimension as well as the cleavage model that gives rise to a set of expectations regarding the relationship between education, authoritarian-libertarian values and electoral behaviour. These expectations are then subjected to testing, before the concluding discussion returns to the implications of the results.

THE CORE OF THE CONFLICT: AUTHORITARIAN-LIBERTARIAN VALUES

The definition of authoritarian-libertarian values remains somewhat contested. In this context I rely on a definition that has been applied 
by a range of different scholars (Feldman 2003; Flanagan 1987; Flanagan and Lee 2003; Kitschelt 1994). To all of these authors, thus, the core concept is that of hierarchy. Authoritarians favour social hierarchy - the rank ordering of individuals in a system with a clear distinction between superior and inferior groups or persons (Flanagan and Lee 2003: 237-43; Kitschelt 1994: 10). Such hierarchies are both natural and right to authoritarians (Jenssen 1993: 122). Libertarians, on the other hand, dislike social hierarchies and prefer the free and equal interaction of people without regard to social positions.

Along with these attitudes to hierarchy go attitudes concerning tolerance for nonconformity (Heatherington and Weiler 2009). Implicit in libertarians' preference for free and equal interaction among people, hence, is a basic respect for and tolerance of other people - including those who deviate from one's own norms or the norms of society. Quite the opposite for authoritarians: those who deviate from conventional norms or who stand outside society should first and foremost be made to comply with the norms of the majority.

Thus, hierarchy and tolerance form the core of the conflict. However, the concrete manifestation of the conflict may vary from one country to another. This means that the underlying values may play out in relation to different issues, depending on the sociopolitical and historical context as well as the parties' mobilization efforts. This point has to be kept in mind when constructing measures of the dimension as the measures need to tap into issues that are contested in a given context (see Evans 2010). But, whether the conflict turns on moral issues such as abortion or homosexuality, as in the US, or on immigration, as in much of Northern Europe, the fundamental conflict is the same (Heatherington and Weiler 2009).

\section{THE EDUCATION CLEAVAGE: A SET OF EXPECTATIONS}

The cleavage concept stands at the centre of classical political sociology and was popularized by the seminal work of Lipset and Rokkan (1967). At present, most scholars in the field (see DeeganKrause 2007; Knutsen and Scarbrough 1995; Mair 2006) draw on Bartolini's and Mair's (1990) three-pronged cleavage definition, 
according to which cleavages consist of three levels of layered conflict: socio-structural, psychological (comprising values and identities; that is, it takes place in people's minds) and organizational (typically in the form of political parties).

When applying the cleavage model in the context of education and authoritarian-libertarian values, the requirements are, hence, that different educational groups hold different value positions as well as group-specific consciousness, and that the groups vote for specific parties - the parties that mobilize on group interests or values. But what are the mechanisms that tie the three levels together for these particular groups?

A starting point can be found in Franklin's conjecture (2010) that socialization constitutes the core of the cleavage model. This squares well with existing research into the relationship between education and authoritarian-libertarian values. Here it is argued that students undergoing organized education in an institutional setting are socialized into accepting the values prevalent within the given institution - not primarily through the curriculum, but more by informal interaction, with peers and teachers, for example. Thus, the content of the socialization will depend on the values dominating the institutions of higher education (see Weil 1985).

While evidence is scant outside the US, the clear findings in that country (see, for example, Dey 1996: 543; Gross and Fosse 2012) as well as similar tendencies observed across a range of other countries (Brooks 2013; Gross and Fosse 2012: 160; Jacobsen 2001: 366; Nakhaie and Brym 2011: 23) regarding the political values (authoritarian-libertarian ones in particular) of academic teachers and researchers - combined with the tendency for former and active students to possess libertarian values (Pascarella and Terenzini 1991: 279; see also the references given above) - indicate that the values dominating institutions of higher education tend to be of the libertarian kind across the Western world. ${ }^{1}$ This, then, is what is reflected in the finding that those who have spent more time in educational institutions - that is, the more highly educated - are more libertarian than those who have spent less time in these institutions - people with lower levels of education (Stubager 2008; see also Emler and Frazer 1999; van de Werfhorst and de Graaf 2004). Regarding the connection between the socio-structural element and the value aspect of the psychological element, it can therefore (in line with previous research) be hypothesized that the 
level of education stands out as the main predictor of authoritarianlibertarian values $(\mathrm{H} 1)^{2}{ }^{2}$

Along with the socialization to certain values goes the development of a certain identity and consciousness. Basically, the possession of education at a given level is likely to lead people to develop some measure of identification with other individuals with similar levels of education, as opposed to individuals with other educations (see also Tajfel 1974). When adding to this identification the value differences between the educational groups as well as the increasing salience of the conflict over these values in political debate (see also Houtman et al. 2008), we might expect that the members of the educational groups develop a consciousness entailing the valuation of the ingroup over the outgroup (Brown 2000). The identity and consciousness factors constitute the second half of the psychological element of the cleavage, implying that individuals with high or low levels of education are hypothesized to identify with their group and side with it in the intergroup conflict that is, possess group-based consciousness (H2).

Regarding the third element of the cleavage, the expectation is that members of the conflicting educational groups vote for parties that represent their values in the political arena. Because of their configuration of values and consciousness, members of the higheducation group are hypothesized to vote for parties with a libertarian value position, while members of the low-education group are hypothesized to vote for parties with an authoritarian position (H3). In analytical terms, this implies that the effect of education on voting is mediated by the values and the consciousness factors. The expectations are depicted in Figure 1, which also serves as an outline of the empirical tests. ${ }^{3}$

\section{DATA, MEASUREMENT AND ANALYTICAL APPROACH}

Measures of all elements of the proposed cleavage are available in a postal survey of Danish voters (between the ages of 18 and 75) conducted by the author in spring 2004. Of 2,000 respondents randomly drawn from the civil register of all Danish citizens, 1,192 returned completed questionnaires, thus yielding a response rate of 60 per cent. The resulting sample for analysis is representative as regards the relevant population on age, gender and geographical origin. ${ }^{4}$ 
Figure 1

The Education Cleavage at the Individual Level

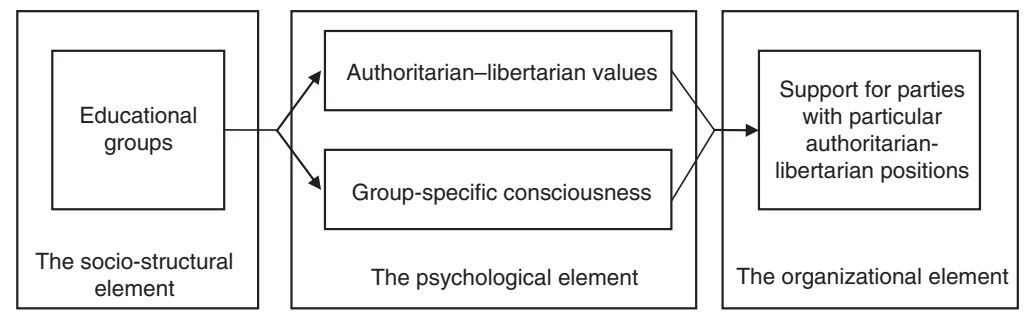

Measurement $^{5}$

Education is measured in five categories ranging from elementary schooling to MA-level and beyond. The variable is, thus, roughly comparable to the United Nations Educations, Scientific and Cultural Organization's (UNESCO) international standard classification of education (ISCED) scheme (see Braun and Müller 1997; see Table 1 for the exact categories). Authoritarian-libertarian values are measured by four Likert-scale items that tap into the core issues of the conflict in the Danish context at the time of the survey: immigration, criminal justice and support for democracy during crises. A confirmatory factor analysis (not shown) clearly supports a one-dimensional structure (just as it differentiates authoritarian and libertarian values from the economic values discussed below), and the responses have therefore been summed to form a scale ranging from 0 to 100 , with 100 being the most authoritarian position.

Education-based identity is tapped by a simple question inspired by traditional measures of partisan and class identification (see, for example, Campbell et al. 1960; Goul Andersen 1997), asking people whether they feel (strongly or somewhat) attached to the high- or low-education group, or to neither. Owing to the low number of respondents identifying strongly with the low-education group, the 'somewhat' and 'strongly' categories for the low-education group have been combined in the analyses while 'don't knows' have been excluded. ${ }^{6}$

Research into class consciousness (Butler and Stokes 1969: 92-3) has documented an asymmetry in the consciousness of dominated and dominating groups. Thus, their study 'certainly shows that the working class is much more prone than the middle class to see 
politics in class terms'. Similarly, Dahrendorf (1959: 284) finds that "those "above" visualize society as a comparatively ordered continuous hierarchy of positions; those "below" are, above all, struck by the gap between them and "the others", . Similar patterns have been found for education (Stubager 2009a). Thus, being the dominant of the groups, the stance of the high-education group is where things can be at stake in the conflict, in the sense that members of the group want to preserve its position, while members of the low-education group may want to challenge it. Educationbased consciousness is assessed by three Likert-scale questions focusing on the role of the high-education group in society. The answers were summed to form a scale ranging from 0 to 100 , with 100 being the most positive evaluation of the role of the higheducation group - that is, an acceptance of its participation in social life and so on (see the Appendix for question wordings).

In order to control for rival explanations (see below), the analyses also included measures of age (in years), income (in thousands of kroner), occupation (measured by a version of the EGP-scheme (Erikson, Goldthorpe, and Portocarero 1979) with seven categories). ${ }^{7}$ Economic values were measured by three Likert-scale items tapping into taxation, (in)equality and government control of private investments. The items were summed to form a scale running from 0 to 100 , with 0 as the most socialist position.

Finally, six parties were included on the measure of party choice (percentage respondents in parentheses): the Social Democrats (26.8), the Social Liberals (10.9), the Conservatives (9.6), the Left Wing (a combination of the Socialist People's Party and the Red-Green Alliance, 9.3), the Liberals (27.7) and the Danish People's Party (11.5). ${ }^{8}$ The parties are on different positions on the authoritarian-libertarian dimension, thereby allowing voters to choose between them on that basis. As shown by Stubager (2010) using the Comparative Manifestoes Dataset ${ }^{9}$ (Budge et al. 2001) and unsurprising to observers of Danish politics - the Social Liberals and, to a somewhat lesser extent, the Left Wing, take up libertarian positions; the Social Democrats, the Conservatives and the Liberals form a centre group, while the Danish People's Party takes an authoritarian position. This implies that, ceteris paribus, highly educated voters should prefer the Social Liberals or - to a lesser extent - the Left Wing, while the Danish People's Party should be favoured by voters with low levels of education. 


\section{Analytical Approach}

The expectations are tested by means of a set of regression models. First, the relationship between education and the variables constituting the psychological element of the proposed cleavage can be examined in a set of OLS regressions - one for each of the variables authoritarian-libertarian values, identity ${ }^{10}$ and consciousness. To investigate the independence of the education cleavage from the historically dominant class cleavage centred on the (re)distribution of wealth, these models will also include measures of income and occupation in order to control for the effect that is due to the economic aspects of education. Likewise, in order to demonstrate the different origin of economic values, these are separately regressed on the set of independent variables included in the other analyses. ${ }^{11}$

The next step in the analyses consists of linking the structural and psychological elements to the organizational. Analytically, this is accomplished by means of a set of block-recursive multinomial logit models (see Dow and Endersby 2004) with party choice as the dependent variable. The models are developed in four steps based on a simple causal ordering of the variables: Model I includes the socio-structural variables; in Model II identity is included; while Model III enters group consciousness as well as economic values to control for economic aspects of the conflict between educational groups. Finally, authoritarian-libertarian values are entered in Model IV. In the presentation, the focus will be on Models I to III, which contain the variables neglected by previous research.

\section{STRUCTURE AND PSYCHOLOGY: THE INFLUENCE OF EDUCATION ON IDENTITY, CONSCIOUSNESS AND VALUES}

The analyses of the connection between the socio-structural and the different aspects of the psychological cleavage elements are presented in Table 1. From the first two columns it can be noted that education is clearly the most important single factor influencing the development of identity. Thus, as expected, members of the educational groups possess some measure of identity in connection with their group membership. This provides support for H2. 
Table 1

The Socio-Structural Origins of Education-based Identity and Group Consciousness, Authoritarian-Libertarian Values and Economic Values: Unstandardized OLS Regression Coefficients, Standard Errors and Explained Variance

\begin{tabular}{|c|c|c|c|c|c|c|c|c|}
\hline & \multicolumn{2}{|c|}{ Identity } & \multicolumn{2}{|c|}{ Group consciousness } & \multicolumn{2}{|c|}{ Authoritarian-libertarian values } & \multicolumn{2}{|c|}{ Economic values } \\
\hline & $b$ & se. & $b$ & se. & $B$ & se. & $b$ & se. \\
\hline Intercept & $2.16 * * *$ & 0.13 & $79.30 * * *$ & 3.94 & $40.04 * * *$ & 4.11 & $52.57 * * *$ & 4.31 \\
\hline Age & 0.00 & 0.00 & $-0.13^{*}$ & 0.06 & -0.05 & 0.06 & $-0.24 * * *$ & 0.06 \\
\hline Education & $* * *$ & & $* * *$ & & $* * *$ & & & \\
\hline Only primary or lower secondary & $1.25 * * *$ & 0.09 & $-18.53 * * *$ & 2.87 & $27.50 * * *$ & 3.00 & -1.74 & 3.14 \\
\hline Upper secondary vocational & $1.02 * * *$ & 0.08 & $-15.84 * * *$ & 2.51 & $24.77 * * *$ & 2.62 & 0.90 & 2.75 \\
\hline Short-cycle tertiary & $0.68 * * *$ & 0.08 & $-8.01 * *$ & 2.56 & $18.61 * * *$ & 2.67 & 4.46 & 2.80 \\
\hline Medium-cycle tertiary & $0.56 * * *$ & 0.08 & $-8.92 * * *$ & 2.53 & $7.67 * *$ & 2.65 & -1.35 & 2.77 \\
\hline Occupation & $* * *$ & & $* * *$ & & $* * *$ & & $* * *$ & \\
\hline Small proprietors/employers & -0.11 & 0.11 & -2.43 & 3.28 & 5.66 & 3.42 & 5.43 & 3.59 \\
\hline Professionals & $-0.33 * * *$ & 0.09 & -0.46 & 2.70 & -3.60 & 2.82 & 2.46 & 2.95 \\
\hline Routine non-manual, higher & $-0.18 *$ & 0.08 & -0.58 & 2.37 & -2.28 & 2.47 & 2.48 & 2.59 \\
\hline Skilled manual workers & -0.01 & 0.10 & $-7.26 *$ & 2.91 & 4.86 & 3.04 & -4.43 & 3.19 \\
\hline Unskilled manual workers & $0.25^{* *}$ & 0.09 & $-8.06 * *$ & 2.68 & 5.43 & 2.80 & $-6.58 *$ & 2.94 \\
\hline Retirees & $-0.19 *$ & 0.09 & -1.59 & 2.68 & $6.75^{*}$ & 2.80 & 5.22 & 2.94 \\
\hline Students & $-0.49 * * *$ & 0.10 & $7.52 *$ & 3.19 & $-9.22 * *$ & 3.33 & $12.91 * * *$ & 3.49 \\
\hline Income & $-0.001 * * *$ & 0.0002 & $0.01 * *$ & 0.01 & 0.01 & 0.01 & $0.05 * * *$ & 0.01 \\
\hline
\end{tabular}

Adjusted $R^{2}$

$$
0.41
$$

$$
0.16
$$

0.23

0.14

Note: ***: significant at the 0.001 level; **: significant at the 0.01 level; *: significant at the 0.05 level. Asterisks for the categorical variables indicate the significance of the entire variable in $F$-tests. Identity runs from 1 to 4 , with 4 being the low-education extreme. The other dependent variables run from 0 to 100, with 100 being the most positive evaluation of the high-education group, or the most authoritarian or capitalist position, respectively. Reference categories are: education: long-cycle tertiary; occupation: routine non-manuals, lower. $\mathrm{N}$ is 966 for identity and 1.026 for all others. 
Similarly, in columns three and four the strong effect of education on consciousness immediately stands out. Thus, there is a difference of more than 18 scale points between the extreme educational categories, with respondents with lower levels of education being clearly less positive in their evaluations than those with higher levels of education (the relationship is almost monotone in shape). This is entirely as expected (H2) and shows the existence of a certain level of animosity between the educational groups.

The final four columns of Table 1 pertain to the authoritarianlibertarian and economic value dimensions. Focusing on the former, the expected influence of education comes out very clearly even when the effects of age, occupation and income have been taken into account. And, as expected, the highly educated are the most libertarian (that is, they have lower scale scores) - a result that has also been found in previous research (see above) and that supports H1. With income being insignificant and the effect of occupation driven mainly by the student category, the results also show the independence of authoritarian-libertarian values from economic factors, thus supporting the view that the values form part of a separate education cleavage.

This view is further supported when inspecting the results for economic values - particularly in contrast to those for authoritarianlibertarian values. Thus, while education is strongly related to the latter, it has no effect on the former. The opposite configuration is found for income, which has a positive relationship with economic values (higher income leads to a more capitalist position), but no effect on authoritarian-libertarian values. In other words, authoritarian-libertarian values are driven mainly by education, while economic values are driven by income and, to some lesser extent, occupation. These results document the structural independence of the two value dimensions, meaning that the authoritarian-libertarian conflict does not represent a new version of the class cleavage. It may be added that with a Pearson correlation of $-0.04(p=0.14)$ the dimensions themselves are also independent.

All in all, in line with previous research, the results of this first set of analyses support the expectations regarding the existence of an education cleavage. The question which is taken up next, however, is whether the variables of the socio-structural and psychological elements also influence electoral behaviour. 


\section{STRUCTURE, PSYCHOLOGY AND VOTING: THE INFLUENCE OF EDUCATION, IDENTITY, CONSCIOUSNESS AND VALUES ON ELECTORAL BEHAVIOUR}

In order to facilitate the interpretation of the results of the multinomial logit analyses of this section I rely on predicted probabilities when presenting the results of the analysis. ${ }^{12}$ Predictions are presented only for the core theoretical variables: education, identity and consciousness. However, Table 2 provides an overview of the results by showing the level of significance of all variables included in the three models.

Looking first at Model I, Table 2 shows that all four variables are significant, albeit income less clearly so than age, education and occupation. In more detail, the upper half of Table 3 reveals that, as expected, the highly educated vote more for the Social Liberals and the Left Wing than do the electorate as a whole, and they clearly shy away from the Danish People's Party. At the other end of the table an almost equally clear pattern can be found among respondents with less than tertiary education. Members of these groups clearly vote less often for the Social Liberals and the Left Wing and more for the Danish People's Party than is the case among all voters. In other words, the attractiveness of the three parties differs strongly across the educational groups (even if it misses statistical significance for the Left Wing).

Table 2

Determinants of Party Choice: Significance of Variables in Multinomial Logistic Regression Models and Model Fit

\begin{tabular}{lcccc}
\hline & Model I & Model II & Model III & Model IV \\
\hline Age & $* * *$ & $* * *$ & $* * *$ & $* * *$ \\
Education & $* * *$ & $* * *$ & $* *$ & \\
Occupation & $* * *$ & $* * *$ & $* * *$ & $* *$ \\
Income & $*$ & & & \\
Identity & & $* *$ & $*$ & $*$ \\
Group consciousness & & & $* *$ & $* *$ \\
Economic values & & & $* * *$ & $* * *$ \\
Authoritarian-libertarian values & 0.23 & 0.27 & 0.43 & $* * *$ \\
Nagelkerke's $R^{2}$ & -1206.25 & -1186.65 & -1100.62 & -987.99 \\
Log likelihood & & &
\end{tabular}

Note: ***: significant at the 0.001 level; **: significant at the 0.01 level; *: significant at the 0.05 level. Significance levels are based on likelihood ratio tests of the combined influence of the variables across all six parties. $\mathrm{N}=776$. 
Table 3

Education, Identity and Party Choice after Controls for Age, Occupation and Income: Predicted Probabilities

\begin{tabular}{|c|c|c|c|c|c|c|}
\hline & Social Liberals & Left Wing & Social Democrats & Conservatives & Liberals & Danish People's Party \\
\hline \multicolumn{7}{|l|}{ Education } \\
\hline Only primary or lower secondary & 0.05 & 0.08 & 0.39 & 0.10 & 0.23 & 0.16 \\
\hline Upper secondary vocational & 0.11 & 0.07 & 0.32 & 0.12 & 0.23 & 0.14 \\
\hline Short-cycle tertiary & 0.18 & 0.07 & 0.36 & 0.06 & 0.23 & 0.11 \\
\hline Medium-cycle tertiary & 0.26 & 0.17 & 0.32 & 0.07 & 0.12 & 0.07 \\
\hline Long-cycle tertiary & 0.25 & 0.20 & 0.38 & 0.05 & 0.10 & 0.01 \\
\hline$\overline{\chi^{2}}$ & $9.60^{*}$ & 4.74 & 2.02 & 5.43 & $16.06^{*}$ & $14.50 * *$ \\
\hline \multicolumn{7}{|l|}{ Identity } \\
\hline Low education & 0.11 & 0.07 & 0.47 & 0.01 & 0.16 & 0.18 \\
\hline Neither/nor & 0.15 & 0.05 & 0.41 & 0.06 & 0.21 & 0.12 \\
\hline Somewhat high education & 0.21 & 0.08 & 0.29 & 0.08 & 0.26 & 0.08 \\
\hline Strongly high education & 0.33 & 0.11 & 0.20 & 0.11 & 0.23 & 0.03 \\
\hline$\overline{\chi^{2}}$ & 4.32 & 1.63 & $10.41^{*}$ & 4.95 & 3.93 & 4.57 \\
\hline
\end{tabular}

Note: **: significant at the 0.01 level; *: significant at the 0.05 level. $\mathrm{N}=776$. Entries are predicted probabilities calculated from Models I (education) and II (identity) in Table 2 of voting for each party by lower routine non-manuals with a short-cycle tertiary education (only for identity) and average age (46 years) and income (280,000 kroner). Significance tests are $\chi^{2}$ tests of equality in the predicted probability of support for a given party across the educational categories. 
When, in Model II, identity is introduced, education remains significant, thereby implying that identity does not completely mediate the effect of education (see Table 2). On the other hand, identity is clearly significant and thereby has an important contribution to explaining voting (see also the increase in the value of Nagelkerke's $R^{2}$ from Model I to II). Further, the lower half of Table 3 shows that, after controlling for the structural variables, the difference in the predicted probability of voting for the Social Liberals between people with a low-education identity and people with a strong high-education identity is 0.22 while it is 0.15 for the Danish People's Party - only in the opposite direction (the differences between the extreme categories are significant at $p<0.05$ for both parties). These results support the expectations entailed in H3 and show that education-based social identity does indeed play a role in influencing voting.

For the Left Wing, however, the differences between the levels of identity are much smaller, while for the Social Democrats they are fairly large, just as there also seem to be (albeit insignificant) effects for the Conservatives and the Liberals. These effects (or lack thereof) are somewhat surprising from the education cleavage perspective and they indicate that education-based identity has other facets than those related to the conflict over authoritarianlibertarian values.

Thus, irrespective of the disassociation between authoritarianlibertarian values and economic factors, the measure of educationbased identity (and evaluations of the high-education group - see below) taps into both economic and non-economic aspects. The non-economic aspects are related to the education cleavage. The economic aspects arise due to the economic consequences associated with differences of education (see Harrits et al. 2009). That is, higher education often leads to higher incomes. As demonstrated, this is not the reason for the association between education and authoritarian-libertarian values, but it may manifest itself in other ways. Thus, the answers to the identity (and group evaluation) question by voters for the Left Wing, the Social Democrats, the Conservatives and the Liberals may be explained in light of the positions - as also perceived by the voters (Stubager 2009b) - of these parties on the parallel economic conflict dimension on which education also plays a role through its effect on income. The Left Wing and the Social Democrats, that is, have 
traditionally adopted a position of defending the interests of the less well-off against those of more wealthy groups. In the economic perspective this accords with the uncovered relationship between identity and party choice. The situation is likewise, only reversed, for the Liberals and the Conservatives, who have traditionally fought for the interests of more wealthy groups.

These considerations are supported by the analysis of Model III, where the evaluations of the high-education group are included along with economic values to control for the economic aspects of the relationship between the educational groups. ${ }^{13}$ As can be seen in the third column of Table 2, the two new variables reduce the significance of education and identity (that is, their effect is mediated), just as they are both clearly significant and add to the explanatory power of the model. While these results come as little surprise for economic values, they provide new and interesting information with regard to the consciousness variable, which has not been included in voting models before. In itself it is, thus, important to note that, like identity, education-based consciousness has a significant influence on voting.

The precise content of the effect of group consciousness is depicted in Figure 2, which shows the predicted probabilities of voting for each party across varying levels of consciousness while the remaining variables are held constant. To provide a sense of the significance of the results, the figure also presents significance tests of the first derivative of the predicted probabilities as consciousness varies between its empirical minimum and maximum.

The first point to note is that, as expected, the Danish People's Party and the Social Liberals are favoured by voters at opposite ends of the evaluation scale: those with negative evaluations prefer the Danish People's Party, while the Social Liberals are more popular among those with positive evaluations of the high-education group. As can be seen, the effects are significant (albeit only at the 0.10 level for the Social Liberals due to the relatively low number of respondents preferring this party). This is entirely in accordance with H3.

Just as was the case with identity, however, support for other parties is also affected by the evaluations. This primarily applies to the Liberals, who get strongest support among voters with positive evaluations of the high-education group. This might reflect uncontrolled aspects of the economic side of the intergroup 
Figure 2

Education-based Group Consciousness and Voting: Predicted Probabilities of Voting for Each Party

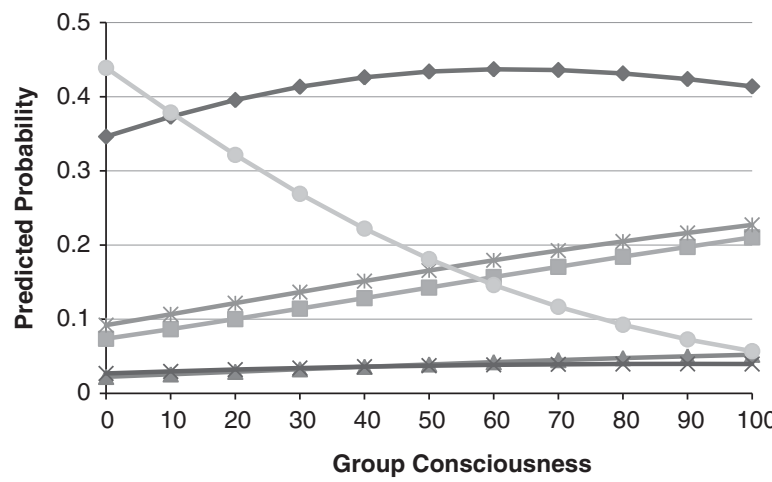

Test of 1st diff.:

Social Liberals: $3.06^{\dagger}$

Left Wing: 0.30

Social Democrats: 0.29

Conservatives: 1.40

Liberals: $4.47^{\star}$

Danish People's

Party: $7.54^{\star \star}$

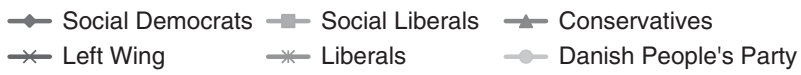

Note: **: significant at the 0.01 level; *: significant at the 0.05 level; ${ }^{\dagger}$ : significant at the 0.10 level. The figure shows the predicted probabilities of voting for each party for lower routine non-manuals with a short-cycle tertiary education, who do not identify with either the high- or the low-education group and who have average age (46 years), income (280,000 kroner) and an average position on economic values (scale score $=58$ ). Test of 1 st differences are $\chi^{2}$ tests of the significance of the change in the predicted probabilities as group consciousness changes from its empirical minimum to maximum.

relationship, but might also stem from a preference among competition-minded liberal voters to side with 'the winners' or the dominant group - the high-education group in this case. While a precise examination of this lies outside the bounds of this article, the results for the Social Liberals and the Danish People's Party document that education - also through the voters' consciousness does play the expected role in relation to electoral behaviour, thereby establishing the connection between the consciousness aspect of the psychological cleavage element and the organizational element.

In Model IV, finally, authoritarian-libertarian values are introduced. As could be expected from previous research, this renders education insignificant. The variable is completely mediated by identity, consciousness and the values, in other words. The other variables exhibit no major changes in their significance. When examining in more detail the effect of authoritarian-libertarian values on voting, the familiar effect emerges (not shown), with large marginal effects 
for the Danish People's Party (+61 percentage points) and the Social Liberals ( -51 percentage points) as the values vary from the libertarian to the authoritarian extreme; no other parties show such clear effects. As noted, these results are not new, but should be mentioned to complete the picture of the education cleavage, just as the fact that they come out as expected serves to reinforce confidence in the other results presented.

\section{CONCLUSION}

In summary, the first set of analyses showed how education is of primary importance in the formation of education-based identity and consciousness as well as authoritarian-libertarian values, thereby documenting a link between the first and second cleavage elements. In contrast, education does not play a significant role for economic values, just as income and occupation play only minor roles as regards the identity, consciousness and authoritarianlibertarian values in focus here. The implications are clear: the education cleavage is something qualitatively different from the economic dimension and the factors behind it such as class. This conclusion was further underscored in the second analytical section where the connections between the socio-structural and psychological elements, on the one hand, and the organizational, on the other, were established. As should be expected from the positions of the parties on the authoritarian-libertarian dimension, high-education respondents prefer the Social Liberals, while loweducation respondents have stronger preferences for the Danish People's Party. Likewise, education-based identity and consciousness as well as authoritarian-libertarian values also influence electoral behaviour in accordance with the expectations, thereby for the first time providing evidence for the importance of education-based identity and group consciousness to voting. All in all, the analyses have thus demonstrated the existence of overlapping conflicts at all three levels and, hence, the existence of the individual-level aspect of an education cleavage.

As noted in the introduction to this article, Denmark should be seen as a critical case for the education cleavage hypothesis in the sense that a failure to identify the cleavage in Denmark would cast serious doubt on its existence in other countries. But the relevance 
of the results outside Denmark might be questioned. Two points stand out as possible answers. First, the results show that, contrary to some claims (such as Dalton 2002; Inglehart 1997), social structure can continue to play an important role for electoral behaviour in Western countries. The existence of the education cleavage indicates that - to the extent that social class is of diminishing importance to electoral behaviour (this point is itself debated: see, for example, the contributions in Evans 1999) - education may be providing an alternative form of structural anchoring to contemporary politics.

Second, it should be noted that the relationship between education and authoritarian-libertarian values has been found in many countries and with increasing strength, just as the value dimension plays an important role in the politics of a number of countries (see Bovens and Wille 2010; Kriesi et al. 2008). Further, the comprehensive comparative study of Austria, France, Switzerland, Germany, the UK and the Netherlands by Kriesi et al. (2008) shows how the electoral importance of education has increased over the past few decades. While in the 1970s there was only a weak effect of education, 'in more recent elections ... we observe that the voters' preferences are more clearly structured by their education level ... We observe here the emergence of a similar potential for a new cleavage across different contexts' (Kriesi et al. 2008: 250). A similar developmental pattern has, incidentally, been found for the Danish case (Stubager 2010). ${ }^{14}$

Given this background, the results presented are useful in pointing to the roots of the conflict in the differing socialization experiences of the educational groups - including their identity development. These roots provide part of the explanation for the intensity of the conflict: they touch on aspects that are deeply ingrained in the individual, aspects that are part of what defines individuals in their own minds. Further, since the socialization mechanisms underlying the cleavage as well as the broader social developments defining the conflicting groups are fairly stable processes, it seems likely that the conflict over authoritarian-libertarian values will continue to have an impact on electoral politics across Western countries for a long time (see also Casal Bértoa 2013), particularly as the group of high-education voters seems to continue to grow (van Deth 1995), thereby making the group more visible to its own members as well as providing a sufficient basis for organizational 
development and the achievement of political power through elections (compare this with the mobilization of the working class in the late nineteenth and early twentieth centuries).

Although rooted in stable processes, the education cleavage may result in all but stable political conditions since the gradual establishment of the cleavage may give rise to challenges to the parties that have dominated in the previous cleavage structure (see, for example, Albertazzi and Mueller 2013; Best 2013; Kitschelt 1994, 1995). By identifying the root of such challenges in a new cleavage, however, we stand a much better chance of understanding them.

The impact of the cleavage may vary over time, depending on the salience of authoritarian-libertarian issues. Hence, during economic crises such as the one ravaging large parts of the (Western) countries at the time of writing, the economic conflict may regain strength and diminish the importance of the education cleavage. ${ }^{15}$ Similarly, the impact may vary depending on the mobilization efforts of the parties. Thus, the parties' appeals to the educational groups either directly or through their values (see Mair 2006: 372) are an integral part of the cleavage, and variation therein therefore influences its strength (see, for example, the corroborating comparative evidence in Ivarsflaten and Stubager 2012). ${ }^{16}$

The socialization basis of the conflict also provides a basis for speculation about the development of an education cleavage outside the Western countries that have been the focus here. Looking to Eastern Europe, for example, the identification of a similar configuration would seem to presuppose the widespread existence of similar socialization experiences. Following Weil (1985) and Brooks (2013: 30), one might speculate on this point that the dominant authoritarian pre-1989 value structure in these countries has meant that significant numbers of highly educated individuals have not experienced the socialization to libertarian values characteristic of similar groups in Western countries. Consequently, the conflict between high- and low-educated groups is possibly not as pronounced in Eastern as in Western Europe. Until generational replacement has exchanged the pre-1989 cohorts with sufficient numbers of individuals socialized under the more libertarian post-1989 regimes, therefore, we should not expect to see the development of similar cleavages in the former communist countries. So far, at least, the analyses of Casal Bértoa (2013) suggest that the electoral politics of East European countries does not (yet?) display the degree of 
stability that would be expected had it been based on cleavages such as the one on education that has been in focus in this article.

\section{APPENDIX}

The variables in the analysis are operationalized as follows:

Education is measured in five categories (with short descriptions and percentage respondents in parentheses): only primary or lower secondary (elementary schooling; 16.5), vocational upper secondary (for example, craftsmen; 36.4), short-cycle tertiary (further vocational education; 18.2, including respondents with a general upper secondary - high school - exam), medium-cycle tertiary (BA-level; 17.8) and long-cycle tertiary (MA-level and beyond; 11.1).

Authoritarian-libertarian values are measured by four Likert-scale items:

- 'Immigration constitutes a serious threat to our national culture';

- 'Violent crimes should be punished far more strictly than they are today';

- 'It would be very sensible to let a strong man seize power in a situation of economic crisis'; and

- 'Islam constitutes a serious threat to Danish culture'. ${ }^{17}$

The response categories were 'completely disagree', 'mostly disagree', 'neither/nor', 'mostly agree', 'completely agree' and 'don't know'. The answers have been summed to form a scale running from 0 to 100 , with 100 as the most authoritarian position (Cronbach's $\alpha$ of $0.69, \mathrm{M}=58.7, \mathrm{SD}=24.0$ ). In the construction of this and all other scales used, missing values (including 'don't knows') on the original variables have been replaced with the mean of the other respondents. This decision does not affect the results of the analyses.

Education-based identity is tapped by the following item:

'People regularly say that there are two groups of people in Danish society: those with high education and those with low education. Would you say that you ...

Feel highly attached to people with high education;

Feel somewhat attached to people with high education;

Don't feel attached to any of the groups;

Feel somewhat attached to people with low education; 
Feel highly attached to people with low education;

Don't know'.

Respondents were distributed with 8.1 per cent in the first category, and 29.3, 42.9, 13.6, 2.2 and 4.0 in the following five.

Education-based consciousness is assessed by the following three Likert-scale questions (with the same response categories as above):

- 'People with high education often want to lead society in a wrong direction';

- 'If people with high education decided more we would have many more problems in society'; and

- 'People with high education don't know how society really works'.

The answers were summed to form a scale ranging from 0 to 100 , with 100 being the most positive evaluation of the high-education group $(\alpha=0.71, \mathrm{M}=64.0, \mathrm{SD}=22.4)$.

Occupation was measured by a version of the EGP-scheme (Erikson, Goldthorpe and Portocarero 1979) containing the following categories (with percentage respondents in parentheses): small proprietors/ employers (6.3), professionals (15.9), routine non-manuals, higher (20.4), routine non-manuals, lower (13.6), skilled manual workers (7.5), unskilled manual workers (10.0), retirees (18.7) and students (7.7). The two last categories were included in order to retain all voter segments in the analysis; the results are, however, robust to their exclusion.

Economic values were measured by three Likert-scale items (response categories as above):

- 'The government has too little control over private investments';

- 'Higher incomes ought to be taxed more than they are today'; and

- 'In politics, one should strive to give everybody the same economic conditions no matter what their education and employment is'.

The items were summed to form a scale running from 0 to 100 , with 0 as the most socialist position $(\alpha=0.59, \mathrm{M}=57.3, \mathrm{SD}=24.2)$.

\section{ACKNOWLEDGEMENTS}

Previous versions of this article have been presented at the IPSA conference in Santiago, June 2009, the annual meeting of the Danish Political Science Association 
in Vejle, November 2009, and the ECPR Joint Sessions of Workshops in Münster, March 2010 as well as at the Department of Political Science, University of Gothenburg, the Department of Comparative Politics, University of Bergen and at Nuffield College, University of Oxford. The article has also benefited from the generous comments of Hanspeter Kriesi, Clem Brooks, Catherine Bolzendahl as well as of the participants in the Government and Opposition workshop in London, April 2012. I am very grateful for all of these contributions to improving the article; all errors and omissions remain my responsibility.

\section{NOTES}

${ }^{1}$ Incidentally, Brooks' (n.d.: 30) finding that East European academics tend to be less libertarian than their Western European, American and Antipodean colleagues fits well with Weil's (1985) thesis about institutions of higher education as repositories of the dominant values of the society. Many of the East European professors in Brooks' analysis have been socialized during the previous authoritarian regimes, that is.

${ }^{2}$ Research by van de Werfhorst and de Graaf (2004) and Stubager (2008) has shown that although field of study exerts some influence, the level of education is clearly the strongest predictor. Hence, I focus on this aspect in the analyses.

${ }^{3}$ Figure 1 depicts the individual-level processes leading to the establishment of the cleavage. It leaves out the role of parties as mobilizing agents - a role they may play by furthering the establishment of the ties between the cleavage elements, for example. A full examination of such processes falls outside the confines of this article.

${ }^{4}$ Details about sampling, survey design, questionnaire and so forth are available from the author upon request.

${ }^{5}$ See the Appendix for all details on measurement.

${ }^{6}$ Unfortunately, the survey did not contain a measure of other types of social identifications (such as class). This means that it is not possible to assess the relative weight of education-based identity just as it is necessary to rely on other variables to control for other identities (see below). Previous research (Stubager 2009a) has, however, documented the usefulness of the measure as well as its relationship with authoritarian-libertarian values. Thus, to the extent that the measure available yields expected results, which it does to a high degree, it seems justified to assume that it is picking up a good deal of what it is assumed to do.

7 The core results are not affected if the class scheme of Kriesi et al. (2008) with its differentiation between sociocultural specialists and managers is used instead.

${ }^{8}$ All other respondents were excluded from the analysis.

${ }^{9}$ Similar results can be found when inspecting surveys of MPs and of voters' placements of the parties on relevant issues.

10 With four categories the identity variable is strictly ordinal. However, since a multinomial logit model (thus avoiding the parallel regression assumption of ordinal models) yields the same results as OLS, the latter has been chosen for ease of presentation. 
11 Preliminary analyses showed that gender plays no significant role either at this level or with regard to voting. In the interest of parsimony, the variable has therefore been kept out of the analysis. The same applies to religion, which has no important role in Danish politics, partly since many Muslim immigrants have not yet obtained the right to vote.

12 The estimated coefficients are available from the author upon request.

13 The absence of a measure of identities other than education makes it necessary to rely on economic values as controls for the psychological aspects of the economic conflict. This may, in effect, imply a conservative test for the effect of the educationbased variables in focus since the value variable, given its closer proximity to voting, may pick up more variation than would more focused measures of class identity and consciousness.

14 Likewise, Ivarsflaten and Stubager (2012) show education to be the strongest sociostructural predictor of voting for parties mobilizing on an authoritarian platform in Austria, Denmark, Flanders, France, the Netherlands, Norway and Switzerland.

15 Evidence from the Danish 2011 election (Hansen and Goul Andersen 2013) suggests, however, that although the economic crisis might have heightened the salience of economic issues, the education cleavage retains its strength.

16 The parties' mobilization efforts may also influence the degree to which EU-related issues become associated with the education cleavage. While Kriesi et al. (2008) find some indications of this in their study, a comparable relationship has not (or not yet) materialized in Denmark (see de Vries 2013).

17 It might be argued that some tenets of the way Islam is practised in some countries are at odds with libertarian ideas such as equality of men and women and the rights of homosexuals, thereby possibly making it difficult for otherwise libertarian-minded respondents to determine whether Islam constitutes a threat to values they cherish. Irrespective of the merits of such considerations, they seem to be of minor relevance in the present context. This is so for at least two reasons. First, the item specifically asks whether 'Islam is a serious threat to Danish culture'. While equality of men and women and protection of the rights of homosexuals are commonly regarded as important by Danish political elites, they are not identical to the vastly more encompassing concept 'Danish culture'. Second, although the above-mentioned argument may be made by political theorists, it does not seem to be common in the Danish population - at least at the time of the survey. Thus, fewer than 4 per cent of the sample gave a 'don't know' reply to the item and it correlates very well with the three others in the scale (the average correlation is $r=0.45$ ). In other words, the respondents had no trouble answering the question and they clearly did so in a manner that was consistent with the notion of a common underlying authoritarian-libertarian value dimension.

\section{REFERENCES}

Albertazzi, D. and Mueller, S. (2013), 'Populism and Liberal Democracy: Populists in Government in Austria, Italy, Poland and Switzerland', Government and Opposition, 48(3): 343-71.

(C) The Author 2013. Published by Government and Opposition Limited and Cambridge University Press 
Bartolini, S. and Mair, P. (1990), Identity, Competition and Electoral Availability (Cambridge: Cambridge University Press).

Best, R. (2011), 'The Declining Electoral Relevance of Traditional Cleavage Groups', European Political Science Review, 3: 279-300.

(2013), 'How Party System Fragmentation has Altered Political Opposition in Western Democracies', Government and Opposition, 48(3): 314-42.

Bovens, M. and Wille, A. (2010), 'The Education Gap in Participation and its Political Consequences', Acta Politica, 45: 393-422.

Braun, M. and Müller, W. (1997), 'Measurement of Education in Comparative Research', Comparative Social Research, 16: 163-201.

Brooks, C. (2013), 'Nations, Classes, and the Politics of Professors: A Comparative Perspective', unpublished manuscript, Department of Sociology, Indiana University.

Brown, R. (2000), 'Social Identity Theory: Past Achievements, Current Problems and Future Challenges', European Journal of Social Psychology, 30: 745-78.

Budge, I., Klingemann, H.-D., Volkens, A., Bara, J. and Tanebaum, E. (2001), Mapping Policy Preferences: Estimates for Parties, Electors, and Governments, 1945-1998 (Oxford: Oxford University Press).

Butler, D. and Stokes, D. (1969), Political Change in Britain: Forces Shaping Electoral Choice (London: Macmillan).

Campbell, A., Converse, P.E., Miller, W.E. and Stokes, D.E. (1960), The American Voter (Chicago: University of Chicago Press).

Casal Bértoa, F. (2013), 'Post-Communist Politics: On the Divergence (and/or Convergence) of East and West', Government and Opposition, 48(3): 398-433.

Clark, T.N. and Lipset, S.M. (1991), 'Are Social Classes Dying?', Journal of Social Issues, 6: $397-410$.

Dahrendorf, R. (1959), Classes and Class Conflict in Industrial Society (Palo Alto, CA: Stanford University Press).

Dalton, R.J. (2002), Citizen Politics: Public Opinion and Political Parties in Advanced Industrial Democracies, 3rd edn (New York: Chatham House).

Deegan-Krause, K. (2007), 'New Dimensions of Political Cleavage', in R.J. Dalton and H.-D. Klingemann (eds), The Oxford Handbook of Political Behavior (Oxford: Oxford University Press): 538-56.

van Deth, J.W. (1995), 'A Macro Setting for Micro Politics', in J.W. van Deth and E. Scarbrough (eds), The Impact of Values (Oxford: Oxford University Press): 48-75.

Dey, E.L. (1996), 'Undergraduate Political Attitudes: An Examination of Peer, Faculty, and Social Influences', Research in Higher Education, 37: 535-54.

Dow, J.K. and Endersby, J.W. (2004), 'Multinomial Probit and Multinomial Logit: A Comparison of Choice Models for Voting Research', Electoral Studies, 23: 107-22.

Emler, N. and Frazer, E. (1999), 'Politics: The Education Effect', Oxford Review of Education, 25: 251-73.

Erikson, R., Goldthorpe, J.H. and Portocarero, L. (1979), 'Intergenerational Class Mobility in Three Western European Societies: England, France and Sweden', British Journal of Sociology, 30: 415-41.

Evans, G. (1999), The End of Class Politics? Class Voting in Comparative Context (Oxford: Oxford University Press). 
(2010), 'Models, Measures and Mechanisms: An Agenda for Progress in Cleavage

Research', West European Politics, 33: 634-47.

Feldman, S. (2003), 'Enforcing Social Conformity: A Theory of Authoritarianism', Political Psychology, 24: 41-74.

Flanagan, S.C. (1987), 'Value Change in Industrial Societies', American Political Science Review, 81: 1303-19.

and Lee, A.-R. (2003), 'The New Politics, Culture Wars, and the AuthoritarianLibertarian Value Change in Advanced Industrial Democracies', Comparative Political Studies, 36: 235-70.

Franklin, M.N. (2010), 'Cleavage Research: A Critical Appraisal', West European Politics, 33: $648-58$.

Goul Andersen, J. (1997), 'Changing Class Cleavages', in O. Borre and J. Goul Andersen (eds), Voting and Political Attitudes in Denmark (Aarhus: Aarhus University Press): 114-59.

Gross, N. and Fosse, E. (2012), 'Why are Professors Liberal?', Theory and Society, 41: $127-68$.

Hansen, K.M. and Goul Andersen, J. (2013), 'En samlet model for partivalg', in R. Stubager, K.M. Hansen and J. Goul Andersen (eds), Krisevalg. Økonomien og folketingsvalget 2011 (Copenhagen: DJØF-Forlag): 187-208.

Harrits, G.S., Prieur, A., Rosenlund, L. and Skjott-Larsen, J. (2009), 'Class and Politics in Denmark: Are Both Old and New Politics Structured by Class?', Scandinavian Political Studies, 32: 1-27.

Heatherington, M.J. and Weiler, J.D. (2009), Authoritarianism and Polarization in American Politics (Cambridge: Cambridge University Press).

Henjak, A. (2010), 'Political Cleavages and Socio-economic Context: How Welfare Regimes and Historial Divisions Shape Political Cleavages', West European Politics, 33: 474-504.

Houtman, D., Achterberg, P. and Derks, A. (2008), Farewell to the Leftist Working Class (New Brunswick, NJ: Transaction Publishers).

Inglehart, R. (1997), Modernization and Postmodernization: Cultural, Economic, and Political Change in 43 Societies (Princeton: Princeton University Press).

Ionescu, G. (1975), Centripetal Politics: Governments and the New Centres of Power (London: Hart-Davis, MacGibbon).

Ivarsflaten, E. and Stubager, R. (2012), 'Voting for the Populist Radical Right in Western Europe: The Role of Education', in J. Rydgren (ed.), Class Politics and the Radical Right (London: Routledge): 122-37.

Jacobsen, D.I. (2001), 'Higher Education as an Arena for Political Socialisation: Myth or Reality?', Scandinavian Political Studies, 24: 351-68.

Jenssen, A.T. (1993), Verdivalg: Ny Massepolitik $i$ Norge (Oslo: Ad Notam Gyldendal).

Kitschelt, H. (1994), The Transformation of European Social Democracy (Cambridge: Cambridge University Press).

(1995), The Radical Right in Western Europe: A Comparative Analysis (Ann Arbor: University of Michigan Press).

Knutsen, O. and Scarbrough, E. (1995), 'Cleavage Politics', in J.W. van Deth and E. Scarbrough (eds), The Impact of Values (Oxford: Oxford University Press): 492-523.

(C) The Author 2013. Published by Government and Opposition Limited and Cambridge University Press 
Kriesi, H., Grande, E., Lachat, R., Dolezal, M., Bornschier, S. and Frey, T. (2008), Western European Politics in the Age of Globalization (Cambridge: Cambridge University Press).

Lipset, S.M. and Rokkan, S. (1967), 'Cleavage Structures, Party Systems, and Voter Alignments: An Introduction', in S.M. Lipset and S. Rokkan (eds), Party Systems and Voter Alignments: Cross-National Perspectives (New York: Free Press): 1-64.

McDermott, M.L. (2009), 'Voting for Myself: Candidate and Voter Group Associations over Time', Electoral Studies, 28: 606-14.

Mair, P. (2006), 'Cleavages', in R.S. Katz and W.J. Crotty (eds), Handbook of Party Politics (London: Sage): 371-5.

Nakhaie, M.R. and Brym, R.J. (2011), 'The Ideological Orientations of Canadian University Professors', Canadian Journal of Higher Education, 41: 18-33.

Pascarella, E.T. and Terenzini, P.T. (1991), How College Affects Students: Findings and Insights from Twenty Years of Research (San Francisco: Jossey-Bass).

Stephens, W.N. and Long, C.S. (1970), 'Education and Political Behavior', Political Science Annual, 2: 3-33.

Stubager, R. (2008), 'Education Effects on Authoritarian-Libertarian Values: A Question of Socialization', British Journal of Sociology, 59: 327-50.

(2009a), 'Education-based Group Identity and Consciousness in the Authoritarian-Libertarian Value Conflict', European Journal of Poltical Research, 48: 204-33.

- (2009b), 'Hvem repræsenterer partierne?', in J. Blom-Hansen and J. Elklit (eds), Perspektiver pa politik (Aarhus: Academica): 38-43.

- (2010), 'The Development of the Education Cleavage: Denmark as a Critical Case', West European Politics, 33: 505-33.

Tajfel, H. (1974), 'Social Identity and Intergroup Behaviour', Social Science Information, 13: 65-93.

de Vries, C. (2013), 'Ambivalent Europeans? Public Support for European Integration in East and West', Government and Opposition, 48(3): 434-61.

van der Waal, J., Achterberg, P. and Houtman, D. (2007), 'Class is Not Dead - It Has Been Buried Alive: Class Voting and Cultural Voting in Postwar Western Societies (1956-1990)', Politics E Society, 35: 403-26.

Weakliem, D.L. (2002), 'The Effects of Education on Political Opinions: An International Study', International Journal of Public Opinion Research, 13: 141-57.

Weil, F.D. (1985), 'The Variable Effects of Education on Liberal Attitudes: A Comparative-Historical Analysis of Anti-Semitism Using Public Opinion Survey Data', American Sociological Review, 50: 458-74.

van de Werfhorst, H. and de Graaf, N.D. (2004), 'The Sources of Political Orientations in Post-Industrial Society: Social Class and Education Revisited', British Journal of Sociology, 55: 211-35. 